\title{
Study on Offloading Operation of Cylindrical FPSO Under Extreme Weather
}

\author{
Hejun Geng ${ }^{1}$, Jiawei Lu $^{2}$, Deling Wang ${ }^{1}$, Jie Wang, ${ }^{1, *}$ \\ ${ }^{1}$ Merchant Marine College, Shanghai Maritime University, Shanghai, China \\ ${ }^{2}$ Shanye Marine Services Co Ltd, Shenzhen, China
}

\section{Email address:}

genghj@shmtu.edu.cn (Hejun Geng), lujiawei@shanye.com.cn (Jiawei Lu), dlwang@shmtu.edu.cn (Deling Wang), wangjie1@shmtu.edu.cn (Jie Wang)

${ }^{*}$ Corresponding author

\section{To cite this article:}

Hejun Geng, Jiawei Lu, Deling Wang, Jie Wang. Study on Offloading Operation of Cylindrical FPSO Under Extreme Weather. American Journal of Traffic and Transportation Engineering. Vol. 6, No. 1, 2021, pp. 22-33. doi: 10.11648/j.ajtte.20210601.13

Received: March 5, 2021; Accepted: March 17, 2021; Published: March 26, 2021

\begin{abstract}
With the wide application of cylindrical FPSO (Floating Production Storage and Offloading, FPSO), more and more people pay attention to its operational safety. To study and explore the safety of cylindrical FPSO offloading operation under extreme weather, it is necessary to conduct the simulation of whole operation process in such conditions. At first, the programming models are formulated for the cylindrical FPSO, shuttle tanker and tugs; then, based on the modelling, the responses of the cylindrical FPSO are simulated during offloading operation under various conditions, combined with Delphin Method and relevant theory. The most unfavorable load state and ultimate wind speed on unfavorable wind direction are explored through three stages: 1. changing the loading status of shuttle tanker and cylindrical FPSO; 2. changing the relative bearing of wind; 3 . changing the wind speed. The results showed that when the offloading state is FPSO half-load $\&$ tanker half-load, it is the worst state to control the offloading system and the limit wind speed in the simulation is: cross wind $\leq 20$ knots.By analyzing the motion response of cylindrical FPSO which is assisted by two tugs, a relatively objective and reasonable solution is obtained, which provides a beneficial reference for the future cylindrical FPSO offloading operation under the extreme weather conditions.
\end{abstract}

Keywords: Cylindrical FPSO, Extreme Weather, Motion Response, Offloading Operation

\section{Introduction}

In recent years, with the development of offshore oil mining technology, many new types of floating offshore platform have been invented. Among them, FPSOs have been widely used for the development of oil-field which are located in deep sea, shallow waters, and marginal offshore with the advantages of strong wind \& waves resistance, big capacity of storage \& offloading, good motion performance, transportability, structure stability, and short construction period [1]. The main FPSOs used recently are conventional ship-shaped FPSOs and new-style cylindrical FPSOs. Compared with ship-shaped FPSO, cylindrical FPSO with the structure of symmetrical arrangement enable it to be more compact, dispensing with turret system and slip rings and reducing the overall cost of facilities. Its superior motion performance and greater rigidity of the whole hull greatly reduce the adaptive requirement of the upper facilities to the floating body motion and deformation [2]. Meanwhile, the cylindrical body of FPSO has a good shielding effect on wind and waves so that more reliable berth in its leeward is available for offloading operation. Therefore, the cylindrical FPSOs are getting more and more widely used in the industry.

At present, thorough researches have been made on the cylindrical FPSO by many scholars in China and abroad. William B. Lamport and Per M. Josefsson have compared the ship-shaped FPSO to the cylindrical FPSO systematically [3]. $\mathrm{Wu}$ introduces and analyzes the features and status of FPSO and sums up the characteristics of the cylindrical FPSO [4]. C. L. Siow et al. conduct the response simulation of a cylindrical FPSO to the motion of surge, sway and heave under the wave action through numerical calculation and 
model test $[5,6]$. Marcos Cueva and Fernando Faria study the hydrodynamic response of heave and pitch motion of cylindrical FPSO in conjunction with the model test and numerical simulation under the various waves action [7]. Wang makes numerical calculation of RAOs of its heave and roll motion under 100-year recurrence sea conditions [8]. Tong et al. study the performance of damping structure of cylindrical FPSO and analyze its forming mechanism of damping and the influence factors of damping characteristics with CFD methods [9]. With the model test methods, Ma analyzes its hydrodynamic characteristics under the irregular waves and rogue waves action and studies the motion response of FPSO and influence factors of the mooring force [10]. In order to reduce the hydrodynamic response of cylindrical FPSO, Ji et al. construct the numerical model of cylindrical FPSO with various taper of anti-motion structure based on fluid dynamics computational method, obtain the damping coefficient through the model calculation, and then propose a new type of cone angle vibration resistant structure [11]. In order to quantify the coupling effects between each component in an offshore floating system and the associated structural response in offshore structure design, Afriana, Rika have presented two kind of analyses, the decoupled analysis and the nonlinear-coupled dynamic analysis in his Master thesis [12]. Meirong Jiang et al. establish a reasonable hydrodynamic model to investigate the damping behavior of the cylindrical FPSO with the heave plate [13]. J. VidicPerunovic, et al. establish a model which is subjected to the Central GoM Hurricane environmental conditions. Through experiment, the feasibility of the concept in the GoM is demonstrated and the importance of viscous effects on motions of the cylindrical unit and of the green water effect is discussed [14]. To analyse the motion of the FPSO in different loading condition, Han K W et al. conduct the study by simulate the motion of FPSO in wave by using commercial software and propose to present the difference of motion response in wave of SEVEN's Cylindrical FPSO when the structure is in full loaded and when it is in ballast condition [15].

Although there are a lot of researches conducting on the cylindrical FPSO, few focuses on its offloading operation. Based on the cylindrical FPSO to be installed in an oil field in South China Sea, this paper explores the marginal conditions upon offloading operation by simulation experiment of the response of cylindrical FPSO with the assistance of two tugs, evaluates the safety and operability of the cylindrical FPSO's offloading operation programme, provides theoretical basis for further guiding the practical offloading operation and avoid the risk in the future.

\section{Overview of the Cylindrical FPSO's Offloading System}

The cylindrical FPSO is embedded into the sea floor by anchor system. While FPSO is fully loaded (draft $=20.8 \mathrm{~m})$, the preload tension force of each anchoring hawser equals to
$1,722 \mathrm{KN}$; while in ballast ( $\mathrm{draft}=18.5 \mathrm{~m}$ ), the force is 1,736 $\mathrm{KN}$. The heading of the cylindrical FPSO is set to $120^{\circ} \mathrm{N}$. The anchor system consists of 12 sea anchors, which are divided into 3 groups, each including 4 anchors. The heading of each group of anchoring hawsers leads $45^{\circ} \mathrm{N}, 165^{\circ} \mathrm{N}$, $285^{\circ} \mathrm{N}$ respectively (the intersection angle between each two groups is $120^{\circ}$ ). The angle between two adjacent anchoring hawsers within each group is $2^{\circ}$ equably. The distance from anchor point to fairlead (chock) is $2,500 \mathrm{~m}$. The anchoring arrangement as shown in Figure 1.

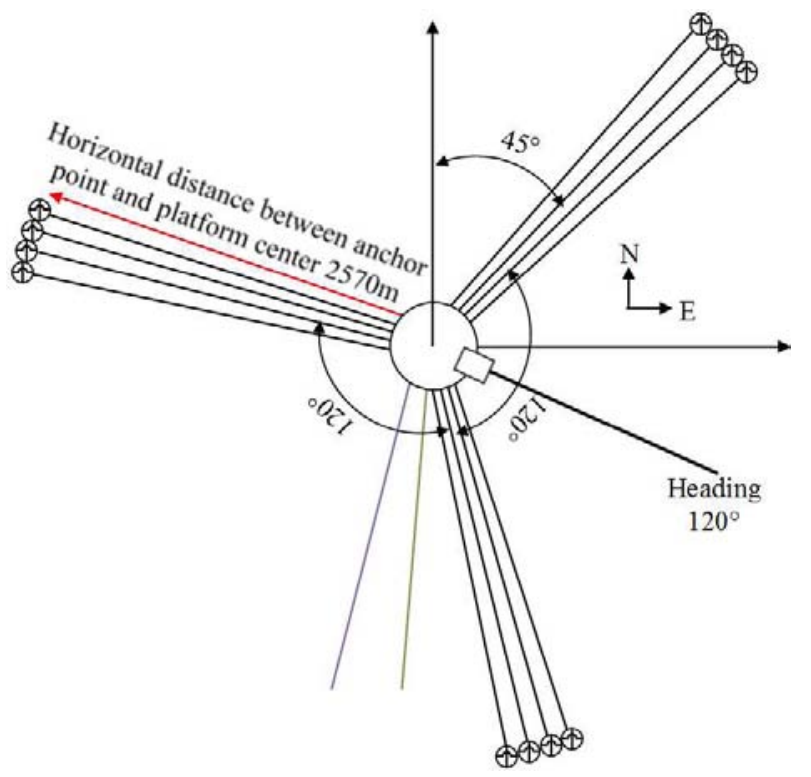

Figure 1. The anchoring arrangement of the cylindrical FPSO.

There mainly prevails northeast and southwest monsoon alternatively in the sea area involved, thus, double offloading arrangements are provided, which set up call points locating in the northeast and southwest part of FPSO respectively. A mooring hawser is to be used to attach the shuttle tanker to the cylindrical FPSO according to the design. In order to maintain the tanker in the offloading position in various winds and currents, two tugs will be deployed to tow the tanker stern from different directions so as to assist the tanker to control its position as required (as shown in Figure 2).

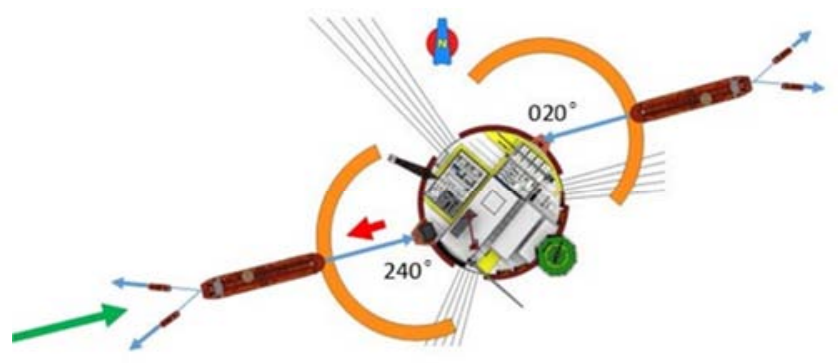

Figure 2. Diagram of the cylindrical FPSO offloading operation.

\subsection{Structural Model of the Cylindrical FPSO}

Cylindrical FPSO is a rounded floating body without selfpropulsion ability, which is embedded into the sea floor with 
anchors. The principal dimensions of the cylindrical FPSO are shown in Table 1 below.

Table 1. Principal dimensions of the cylindrical FPSO.

\begin{tabular}{ll}
\hline Parameters & Values (m) \\
\hline Diameter of water plane & 72 \\
Diameter of the bottom & 94 \\
Diameter of main deck & 82.8 \\
Height of main deck & 33 \\
Diameter of working deck & 90 \\
Height of working deck & 39 \\
Height of double bottom & 2.4 \\
Draft under full-loaded operation condition & 22.8 \\
Draft under half-loaded operation condition & 17.4 \\
Draft under in-ballast operation condition & 16.5 \\
Draft under in-ballast survival condition & 18.5 \\
\hline
\end{tabular}

Three-dimensional model of cylindrical FPSO is established by using the structural type and parameters as well as the stability calculation booklet, as shown in Figure 3.

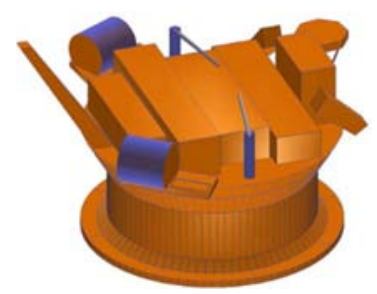

Figure 3. Three-dimensional model of the cylindrical FPSO.

\subsection{Ship Models}

The dead weight of the shuttle tankers used in the South China Sea is normally between 50,000 tons and 100,000 tons. In the simulation experiment, a 75,000-ton tanker is selected as the shuttle tanker offloading from the cylindrical FPSO. In addition, during the offloading operation, two tugs are used to assist the shuttle tanker. The principal parameters of each ship are shown in Table 2, and the model of the ship's wet surface is shown in Figure 4.

Table 2. Principal parameters of shuttle tanker and tugs.

\begin{tabular}{|c|c|c|c|c|}
\hline \multirow{2}{*}{ Parameters } & \multicolumn{2}{|c|}{ Shuttle tanker } & \multirow{2}{*}{ Tug A } & \multirow{2}{*}{ Tug B } \\
\hline & Full-loaded & In-ballast & & \\
\hline Length overall (m) & 228.6 & & 74.1 & 30.8 \\
\hline $\operatorname{LOA}(\mathrm{m})$ & 218.7 & & 64.2 & 28.8 \\
\hline Beam (m) & 32.24 & & 18.0 & 11.1 \\
\hline $\operatorname{Draft}(\mathrm{m})$ & 16.06 & 9.73 & 6.4 & 3.5 \\
\hline Displacement (mt) & 98,800 & 41,100 & 5871.45 & 615 \\
\hline DWT (mt) & 83,890 & & 2,693 & 230 \\
\hline Maximum BP (t) & --- & & 163.5 & 73.0 \\
\hline Quantity of main engine & 1 & & 4 & 2 \\
\hline Type of main engine & diesel & & diesel & diesel \\
\hline Power of main engine $(\mathrm{kw})$ & 8017 & & $2 \times 2720+2 \times 2040$ & $2 \times 1838$ \\
\hline Maximum advance speed (kts) & 18.1 & 18.5 & 16.0 & 12.5 \\
\hline Quantity of propellers & 1 & & 2 & 2 \\
\hline Power of bow thruster (t) & Nil & & $2 \times 12.3$ & Nil \\
\hline Power of stern thruster (t) & Nil & & $1 \times 12.3$ & Nil \\
\hline
\end{tabular}

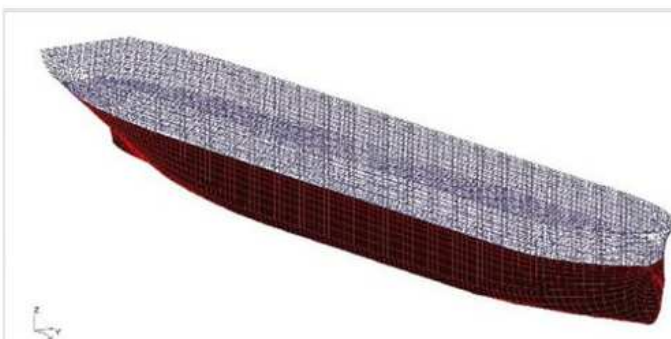

(a) Model of shuttle tanker's wet surface (full-loaded).

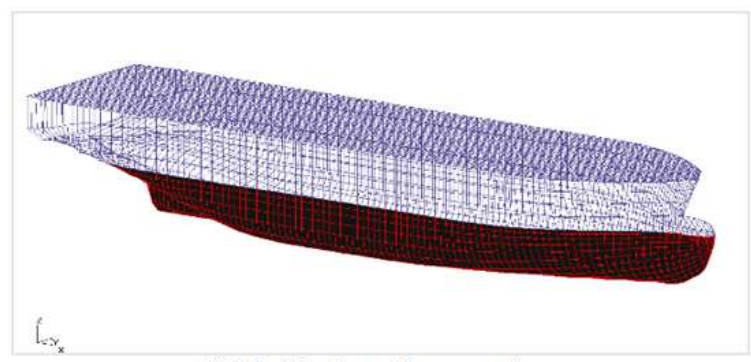

(c) Model of tug A's wet surface.

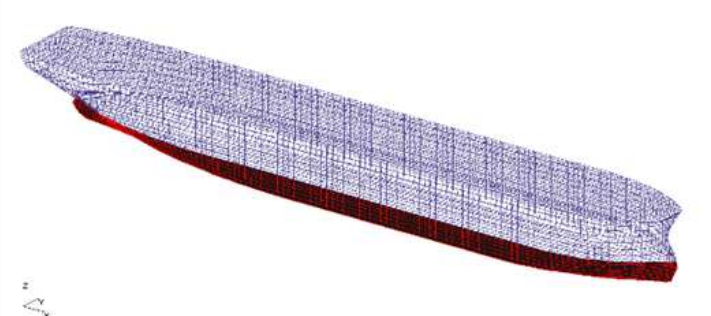

(b) Model of shuttle tanker's wet surface (in-ballast).

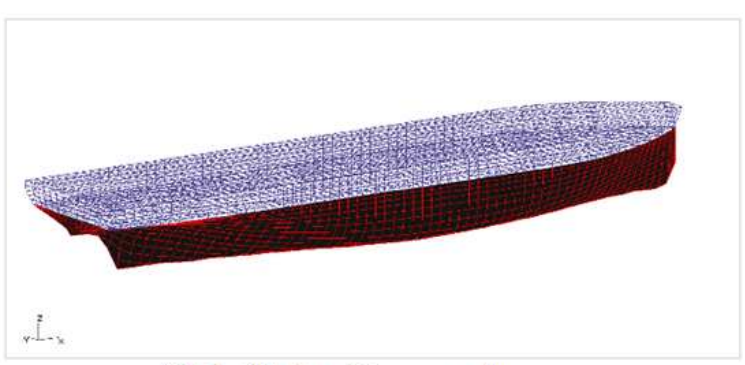

(d) Model of tug B's wet surface.

Figure 4. Model of each ship's wet surface. 


\section{Analysis Methods on Offloading Operation}

Based on the data of three kinds of floating bodies, including cylindrical FPSO, shuttle tanker and tugs, as well as hydrodynamic analysis result, the mathematical model of offloading operation system is established using time domain coupled dynamic analysis software AQWA. The interaction between the marine environment and the three kinds of floating body under the influence of wind, wave and current is analyzed. Then, the cylindrical FPSO motion characteristics during offloading operation is studied.

\subsection{Static Analysis}

In the static analysis, it is mainly focused on the variation of tension force of the mooring hawser and towing hawsers acting on the shuttle tanker under the static equilibrium state. The diagram of force analysis on the offloading operation is shown in Figure 5.

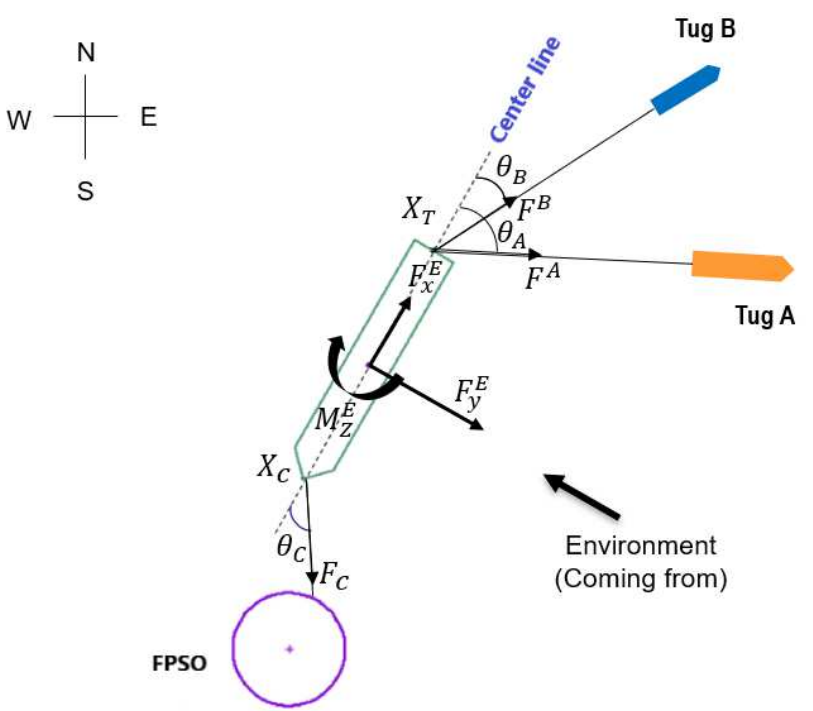

Figure 5. Diagram of force analysis on the cylindrical FPSO offloading operation.

The model for static tension calculation of the hawsers is expressed as follows:

$$
\begin{gathered}
F_{x}^{E}=F_{x}^{T}-F_{x}^{C} \\
M_{z}^{E}=X_{T} F_{y}^{T}-X_{C} F_{y}^{C} \\
{\left[\begin{array}{ll}
(M+A)^{11} & (M+A)^{12} \\
(M+A)^{21} & (M+A)^{22}
\end{array}\right]\left[\begin{array}{l}
\ddot{x}(t)^{1} \\
\ddot{x}(t)^{2}
\end{array}\right]+\left[\begin{array}{ll}
\int_{0}^{t} h^{11}(t-\tau) & \int_{0}^{t} h^{12}(t-\tau) \\
\int_{0}^{t} h^{21}(t-\tau) & \int_{0}^{t} h^{22}(t-\tau)
\end{array}\right][} \\
\text { Where, }(M+A)^{i, j} \text { represents the mass inertia matrix and } \\
\text { additional mass inertia matrix of } i \text { floating body exerted by } j \\
\text { floating body; }(t-\tau) \text { is the delay function matrix of } i \text { floating }
\end{gathered}
$$
body exerted by $j$ floating body; $K^{i}$ is the hydrostatic
Where, $F_{x}^{E}$ is the longitudinal component of the resultant force acting on the shuttle tanker exerted by the mooring hawser and the towing hawsers; $F_{x}^{C}$ and $F_{y}^{C}$ are the longitudinal and transverse forces exerted by the mooring hawser acting on the shuttle tanker; $F_{x}^{T}$ and $F_{y}^{T}$ are the longitudinal and transverse forces exerted by the towing hawsers acting on the shuttle tanker; $M_{Z}^{E}$ is the rotational moment acting on shuttle tanker on the horizontal plane; $X_{C}$ and $X_{T}$ are the distances between the acting points of force exerted by the mooring hawser and the towing hawsers on the shuttle tanker (fairleads) and the middle point of the ship respectively.

$$
\begin{gathered}
F^{C}=\frac{F_{y}^{C}}{\sin \theta_{c}} \\
F_{x}^{C}=F^{C} \cos \theta_{c} \\
F^{T}=\sqrt{\left(F_{x}^{T}\right)^{2}+\left(F_{y}^{T}\right)^{2}}
\end{gathered}
$$

Where, $F^{C}$ is the force exerted by the mooring hawser acting on the shuttle tanker; $\theta_{C}$ is the angle between the mooring hawser and center line of the shuttle tanker on the horizontal plane; $F^{T}$ is the resultant force exerted by the towing hawsers acting on the shuttle tanker.

The resultant force exerted by two tugs acting on the shuttle tanker is calculated as follows:

$$
\begin{gathered}
F_{x}^{T}=F^{A} \cos \theta_{A}+F^{B} \cos \theta_{B} \\
F_{y}^{T}=F^{A} \sin \theta_{A}+F^{B} \sin \theta_{B}
\end{gathered}
$$

Where, $F^{A}$ and $F^{B}$ represent the towing forces exerted by tug $\mathrm{A}$ and tug $\mathrm{B}$ acting on the shuttle tanker respectively; $\theta_{A}$ and $\theta_{B}$ represent the angles between the tug A's hawser and tug B's hawser and center line of the shuttle tanker on the horizontal plane respectively.

\subsection{Dynamic Analysis}

Within the system composing of multi-floating bodies the cylindrical FPSO and shuttle tanker are acted upon by the forces exerted by the winds, wave, current, anchoring, towing hawser and tension of the mooring hawsers between these two floating bodies. So, the equation of motion in time domain are built and solved using the coupling matrix equation: restoring force matrix of $i$ floating body; $x(t)^{i}$ is the motion vector of $i$ floating body; $F_{\text {all }}^{i}$ is the total external force vector exerted upon $i$ floating body, including the first and second order components of forces exerted by the winds, waves, currents, anchoring, towing hawser and mooring hawser 
between two floating bodies.

The time and frequency domain response analysis and calculation are conducted for anchoring and offloading systems of floating body with hydrodynamic analysis software. First of all, calculations of $(M+A)^{i, j}$, RAO and QTF matrix are made in frequency domain. Then, the parameters such as $K^{i}, h^{i, j}(t-\tau)$, and time history of wave force are taken. Finally, the time domain response calculation is done, the motion response of the offloading system during shuttle tanker alongside is analyzed.

According to relevant specifications of 'Classification of Mooring Systems for Permanent Offshore Units [12], APIRP-2SK ${ }^{1}$ and OCIMF (Oil Companies International Marine Forum), the designed values such as tension, displacement and angle are defined as follows:

$$
T_{D}=T_{M}+a T_{s}
$$

Where $T_{D}$ represents the designed tension of the mooring hawser, $T_{M}$ represents the average value of the maximum target value under sample $\mathrm{n}$ analyses, $T_{S}$ represents the standard deviation of the maximum target value under sample $\mathrm{n}$ analyses, and $a$ is the scaling factor.

\section{Simulation Scheme and Analysis of Simulation Results}

\subsection{Simulation Evaluation Criteria}

According to the expert evaluation methods (Delphin Method) and common practices in the offshore engineering, the controllability and the berth available are identified as evaluation criteria considering the tension and angle of the mooring hawser during the offloading operation.

\subsubsection{Controllability}

The pulling force which is exerted by the towing hawser should normally not exceed $60 \%$ of the bollard pull of a tug (BP of tug A should not exceed 98.1t and that of tug B not exceed 43.8t). In any half an hour the frequency of force $100 \mathrm{t}$ or more acting upon the mooring hawser should not be more than 3 times (The higher the frequency, the worse the controllability), and the maximum force no more than $200 \mathrm{t}$ (approximately $1 / 3$ breaking strength) at a time.

\subsubsection{Berth Available}

There are three evaluation criteria for the berth available: first, the direction of the mooring hawser relative to the FPSO (when viewed from aft to forward of FPSO, left - right + ); second, the angle between the two towing hawsers; third, the angle between the towing hawser and the center line of shuttle tanker.

The safe range of the angle $\theta_{C}$ hereinafter referred to as 'direction of mooring hawser relative to FPSO', which is

1 Standard name: Design And Analysis Of Stationkeeping Systems For Floating Structures. between the mooring hawser and axial line of fairlead located in the offloading installation (the line drawn the center of FPSO from fairlead $)$, is $\pm\left(0^{\circ} \sim 45^{\circ}\right)$.

If there are two tugs attached to the stern of the shuttle tanker, the angle between the two towing hawsers should not be less than $30^{\circ}$ to prevent the tugs from collision with each other;

If two tugs are attached to the stern of the shuttle tanker, the angle between either towing hawser and the center line of the shuttle tanker should not exceed $70^{\circ}$ on its very side (relative to the other tug); and it shall not exceed $40^{\circ}$ on the opposite side (the angle between two towing hawsers should not be less than $30^{\circ}$ ). In other words, direction of towing hawser of tug $\mathrm{A}$ and $\mathrm{B}$ relative to shuttle tanker should be within the range of $\left(140^{\circ} \sim 250^{\circ}\right)$ and $\left(110^{\circ} \sim 220^{\circ}\right)$ respectively (measured in Circular notation, viewed from center of shuttle tanker, the forward is $0^{\circ}$, the starboard beam is $90^{\circ}$, the aft is $180^{\circ}$, the port beam is $270^{\circ}$ ).

\subsection{Simulation Scheme and Result Analysis}

According to various loading conditions, the combination of the cylindrical FPSO and shuttle tanker has the following three status during the simulation of offloading operation:

Status A: FPSO in full-loaded \& shuttle in ballast

Status B: FPSO in ballast \& shuttle in full-loaded

Status C: FPSO in full-loaded \& shuttle in full-loaded

In the Chinese coastal waters, during the period of northeast monsoon, wind blowing from the northeast direction is relatively stable, and during the period of the southwest monsoon, wind direction is more variable. Therefore, during the period of southwest monsoon, it is more difficult to keep the shuttle tanker within a safe working area, and during the period of northeast monsoon a little easier. Thus, the northeast offloading point of cylindrical FPSO is selected to determine the working condition in the extreme weather.

\subsubsection{Determination of the Most Unfavorable Offloading Operation Status}

The winds $8 \mathrm{~m} / \mathrm{s}$ (approximate $16 \mathrm{kts}$ ) from abeam of the shuttle tanker is regarded as the principal working condition in the simulation scheme. The three statuses offloading operation are simulated under principal working condition, then the most unfavorable operation status on berthing is identified, i.e. the status with the worst simulated result. The scenarios designed as shown in Table 3.

At the beginning of simulation, the initial position of shuttle tanker is located in the northeast of FPSO. When the parameters of natural conditions such as wind, wave, current, etc. are input into the system, the shuttle tanker begins to move west (leeward). If the direction and magnitude of towing forces exerted by two tugs are adjusted, the shuttle tanker will tend to be stable. The values of evaluation parameters under different offloading status are shown in Table 4, while the time history curves of the force exerted by mooring hawser are shown in Figure 6. 
Table 3. Designed scheme of simulated scenarios.

\begin{tabular}{|c|c|c|c|c|}
\hline Scenario & & SA-01 & SA-02 & SA-03 \\
\hline \multirow{2}{*}{ FPSO } & Loading condition & fullload & halfload & ballast \\
\hline & Hawser length (m) & 100 & 100 & 100 \\
\hline \multirow{2}{*}{ Current } & Speed (kts) & 1 & 1 & 1 \\
\hline & Direction $\left({ }^{\circ} \mathrm{N}\right)$ & 290 & 290 & 290 \\
\hline \multirow{3}{*}{ Wind } & Speed (kts) & 16 & 16 & 16 \\
\hline & Direction $\left({ }^{\circ} \mathrm{N}\right)$ & 110 & 110 & 110 \\
\hline & Height (m) & 1.5 & 1.5 & 1.5 \\
\hline \multirow[t]{3}{*}{ Sea wave } & Period (s) & 4.3 & 4.3 & 4.3 \\
\hline & Direction $\left({ }^{\circ} \mathrm{N}\right)$ & 110 & 110 & 110 \\
\hline & Loading condition & ballast & halfload & fullload \\
\hline \multirow[t]{2}{*}{ Shuttle tanker } & Initial heading $\left({ }^{\circ} \mathrm{N}\right)$ & 200 & 200 & 200 \\
\hline & Initial speed (kts) & 0 & 0 & 0 \\
\hline
\end{tabular}

Table 4. Test results under different offloading conditions.

\begin{tabular}{lll}
\hline Index parameter / Scenario & SA-01 & SA-02 \\
\hline Max tension of mooring hawser $(t)$ & 92 & 135 \\
The frequency of force 100 t or more acting upon the mooring hawser in any half an hour & 0 & 14 \\
Direction of mooring hawser relative to FPSO $\left(^{\circ}\right)$ & $(-30,-10)$ & $(-49,-45)$ \\
Towing force of tug A $(t)$ & 30 & 40 \\
Towing force of tug B $(t)$ & $(20,30)$ & 35 \\
Direction of towing hawser of tug A relative to shuttle tanker $\left(^{\circ}\right)$ & 230 & 230 \\
Direction of towing hawser of tug B relative to shuttle tanker $\left(^{\circ}\right)$ & $(180,200)$ & 200 \\
Angle between both towing hawsers $\left(^{\circ}\right)$ & $(30,50)$ & 30 \\
\hline
\end{tabular}
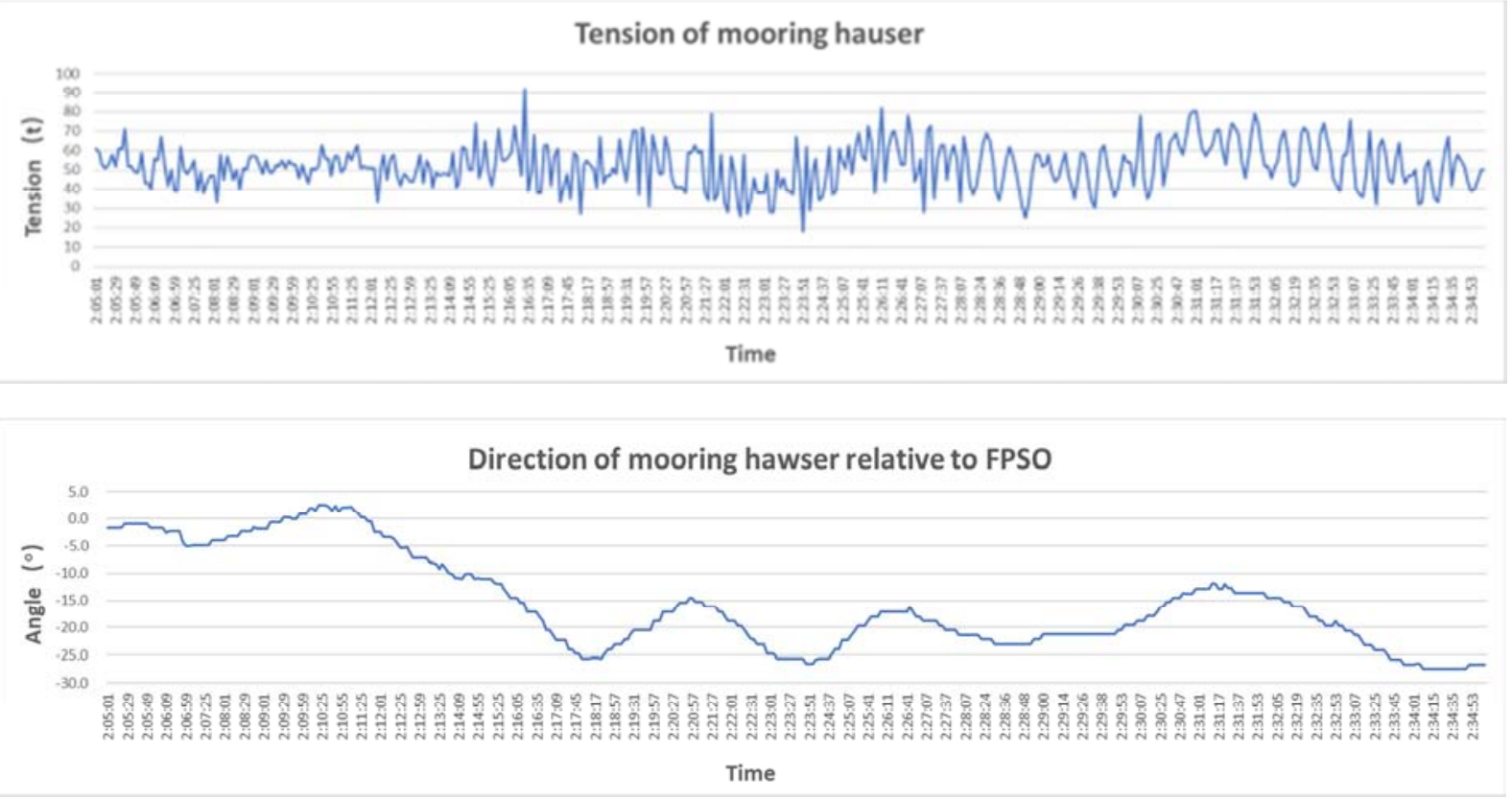

(a) The time history curves of the force exerted by mooring hawser in scenario SA-01.

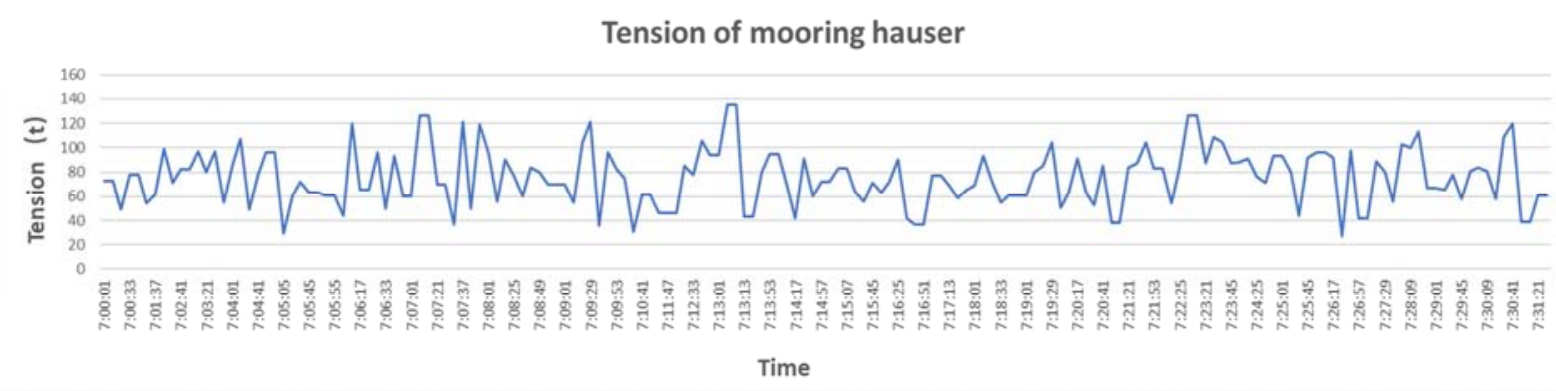




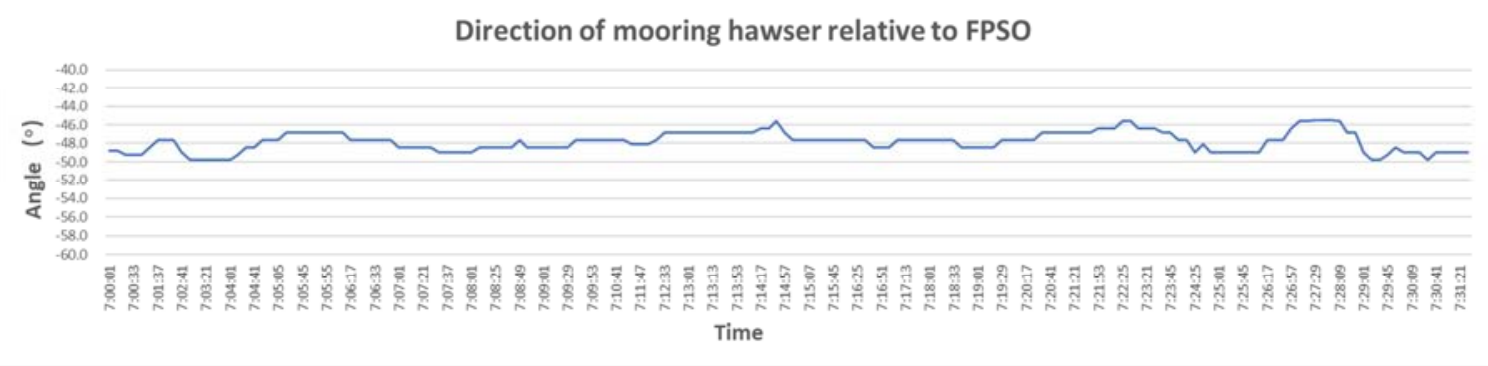

(b) The time history curves of the force exerted by mooring hawser in scenario SA-02.
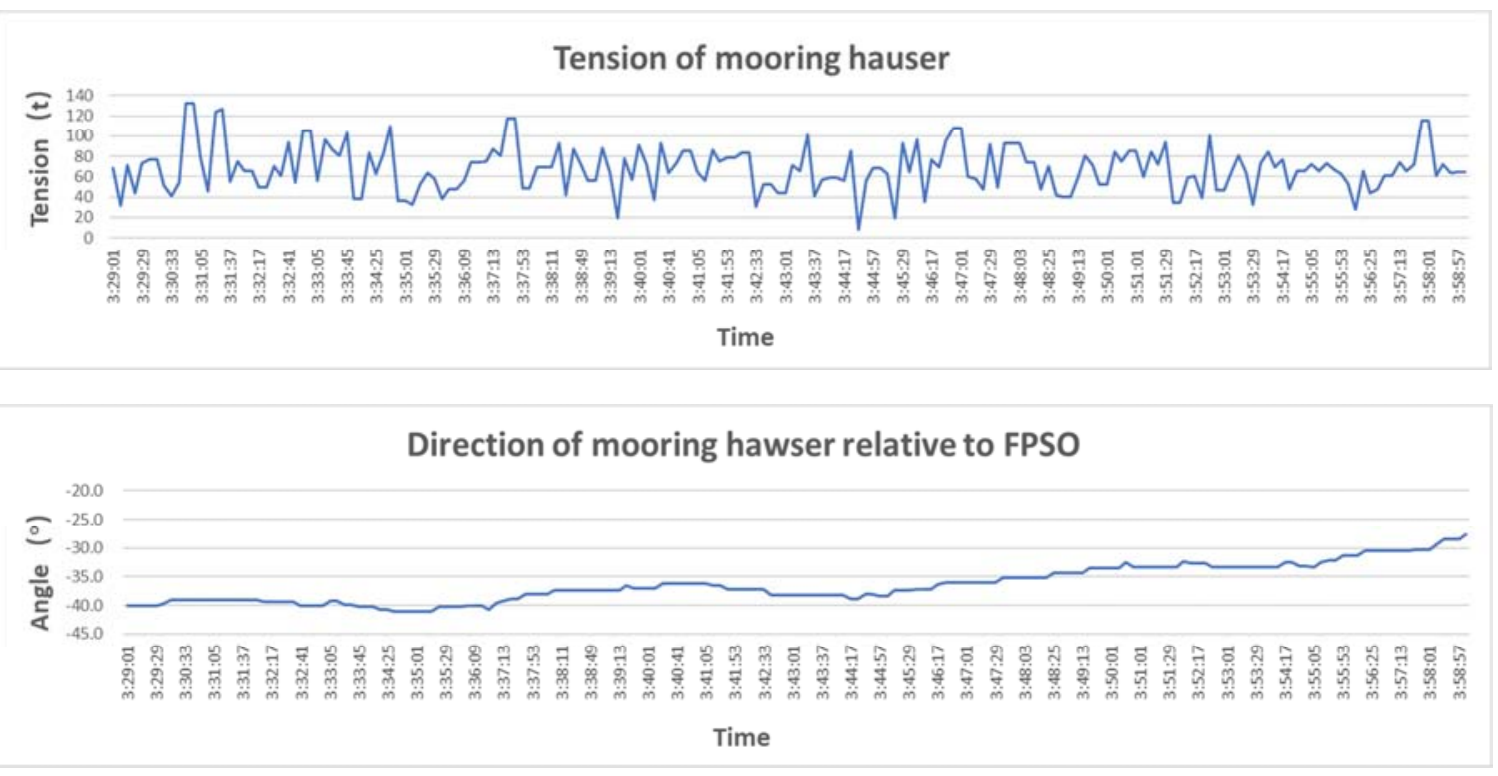

(c) The time history curves of the force exerted by mooring hawser in scenario SA-03.

Figure 6. The time history curves of the force exerted by mooring hawser under different offloading conditions.

A comparison of the results simulated through scenarios SA-01, SA-02 and SA-03 shown in Table 4 and Figure 6 indicates that, in scenario SA-02, the frequency of force $100 \mathrm{t}$ or more acting upon the mooring hawser in any half an hour arrives at 14 (the most frequent), maximum tension $135 \mathrm{t}$, the direction of mooring hawser relative to FPSO is within the interval $\left(-49^{\circ},-45^{\circ}\right)$, both the tension acting upon the mooring hawser and direction of mooring hawser relative to FPSO are beyond the safe margin, therefore, it can be regarded as the worst status, that is to say, it is the greatest challenge to control the system under the status B (FPSO and shuttle tanker all in half-loaded condition).

\subsubsection{Determination of the Most Unfavorable Wind Direction Under the Most Unfavorable Offloading Operation Status}

Based on the status B (FPSO and shuttle tanker all in halfloaded condition), the scenarios which the winds $8 \mathrm{~m} / \mathrm{s}(16$ kts) blow from the bow, $45^{\circ}$ forward of port beam, port beam, $45^{\circ}$ abaft port beam and stern of the shuttle tanker are designed and simulated. Two working conditions with relatively good results from the above-mentioned 5 simulated scenarios are picked out. The scenarios designed as shown in Table 5 .

Table 5. Designed scheme of simulated scenarios.

\begin{tabular}{|c|c|c|c|c|c|c|}
\hline Scenario & & SA-04 & SA-05 & SA-06 & SA-07 & SA-08 \\
\hline & Loading condition & halfload & halfload & halfload & halfload & halfload \\
\hline FPSO & Hawser length (m) & 100 & 100 & 100 & 100 & 100 \\
\hline \multirow{2}{*}{ Current } & Speed (kts) & 1 & 1 & 1 & 1 & 1 \\
\hline & Direction $\left({ }^{\circ} \mathrm{N}\right)$ & 20 & 335 & 290 & 245 & 200 \\
\hline \multirow{2}{*}{ Wind } & Speed (kts) & 16 & 16 & 16 & 16 & 16 \\
\hline & Direction $\left({ }^{\circ} \mathrm{N}\right)$ & 200 & 155 & 110 & 65 & 20 \\
\hline \multirow{3}{*}{ Sea wave } & Height (m) & 1.5 & 1.5 & 1.5 & 1.5 & 1.5 \\
\hline & Period (s) & 4.3 & 4.3 & 4.3 & 4.3 & 4.3 \\
\hline & Direction $\left({ }^{\circ} \mathrm{N}\right)$ & 200 & 155 & 110 & 65 & 20 \\
\hline \multirow{3}{*}{ Shuttle tanker } & Loading condition & halfload & halfload & halfload & halfload & halfload \\
\hline & Initial heading $\left({ }^{\circ} \mathrm{N}\right)$ & 200 & 200 & 200 & 200 & 200 \\
\hline & Initial speed (kts) & 0 & 0 & 0 & 0 & 0 \\
\hline
\end{tabular}


The values of evaluation parameter obtained from simulated scenarios listed in Table 5 are shown in Table 6 , and the time history curves of force exerted by the mooring hawser are shown in Figure 7.

Table 6. Test results with different wind direction under B status.

\begin{tabular}{llllll}
\hline Index parameter / Scenario & SA-04 & SA-05 & SA-06 & SA-07 & SA-08 \\
\hline Max tension of mooring hawser $(t)$ & 50 & 102 & 104 & 92 \\
$\begin{array}{l}\text { The frequency of force } 100 \text { t or more acting upon the } \\
\text { mooring hawser in any half an hour }\end{array}$ & 0 & 1 & 2 & 0 & 90 \\
$\begin{array}{l}\text { Direction of mooring hawser relative to FPSO }\left(^{\circ}\right) \\
\text { Towing force of tug A }(t)\end{array}$ & $(-5,-1)$ & $(-26,-19)$ & $(-36,-30)$ & $(-33,+3)$ vary considerably $(+5,+65)$ maximum variation \\
Towing force of tug B $(t)$ & 15 & 35 & 40 & $(10,35)$ frequent adjustment $(10,50)$ frequent adjustment \\
$\begin{array}{l}\text { Direction of towing hawser of tug A relative to shuttle } \\
\text { tanker }\left(^{\circ}\right)\end{array}$ & 200 & 225 & 240 & 233 & 215 \\
$\begin{array}{l}\text { Direction of towing hawser of tug B relative to } \\
\text { shuttle tanker }\left(^{\circ}\right)\end{array}$ & 160 & 190 & 200 & 193 \\
Angle between both towing hawsers $\left(^{\circ}\right)$ & 40 & 35 & 40 & 40 & 145 \\
\hline
\end{tabular}

\section{Tension of mooring hauser}

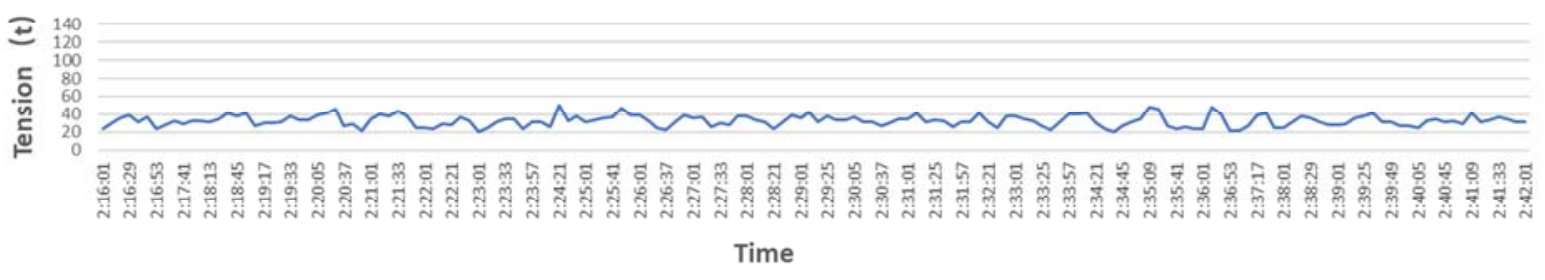

Direction of mooring hawser relative to FPSO

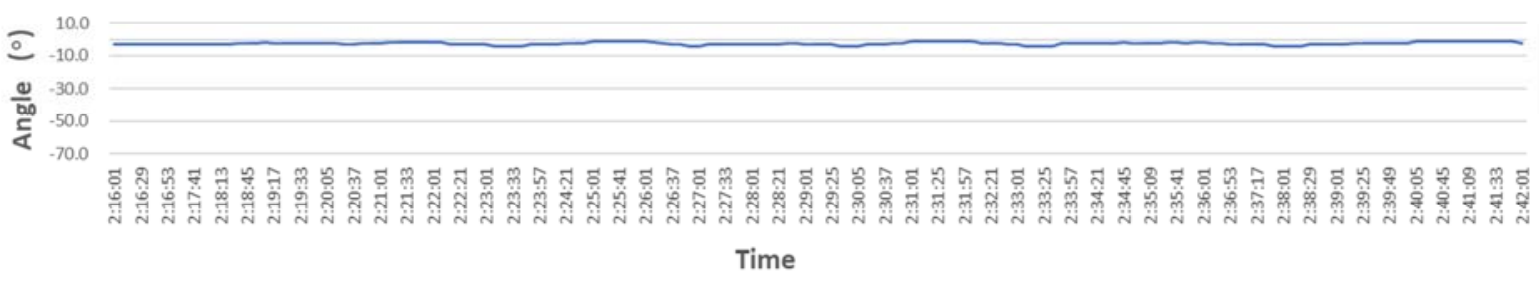

(a) The time history curves of the force exerted by mooring hawser in scenario SA-04.

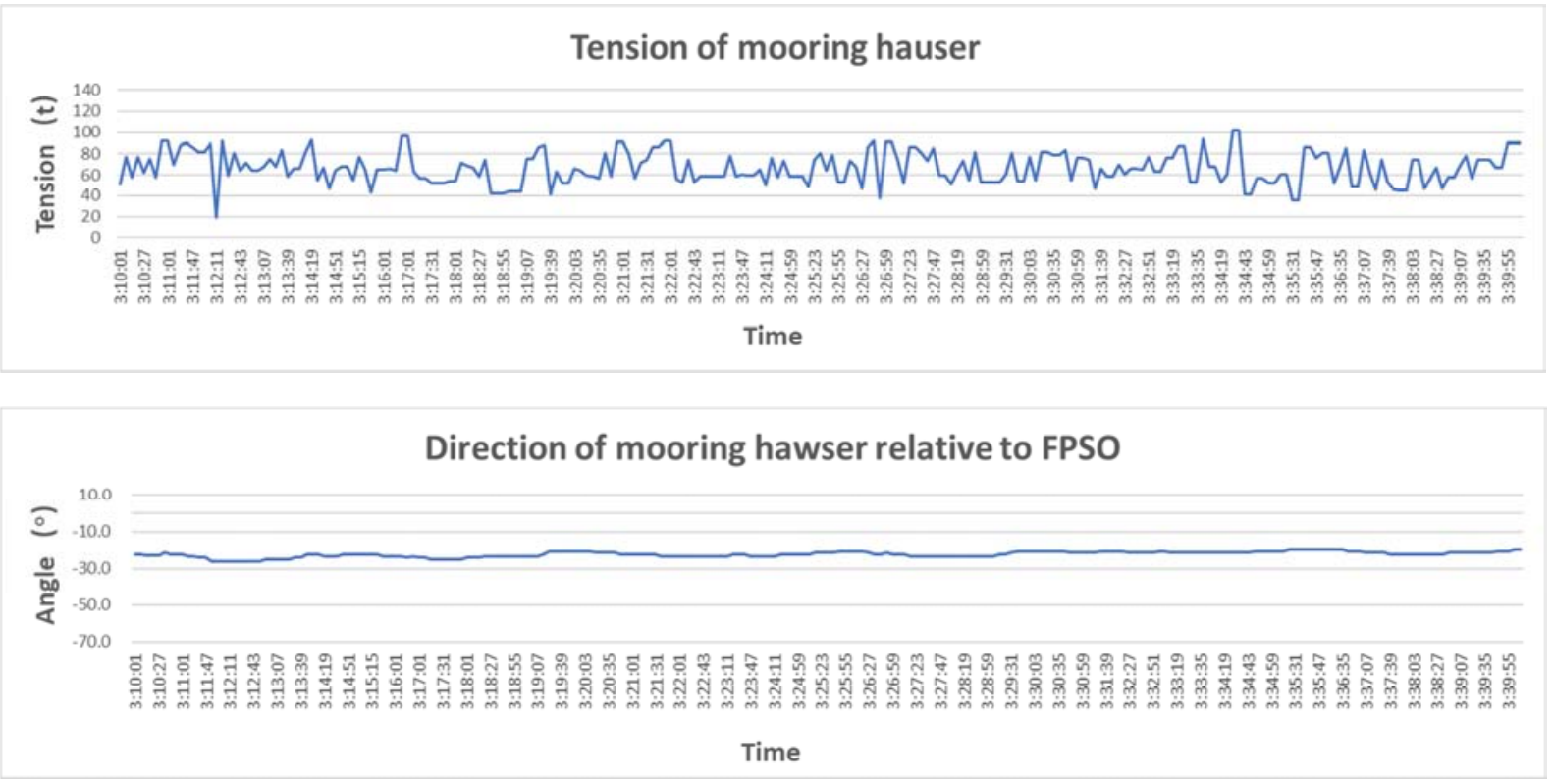

(b) The time history curves of the force exerted by mooring hawser in scenario SA-05. 


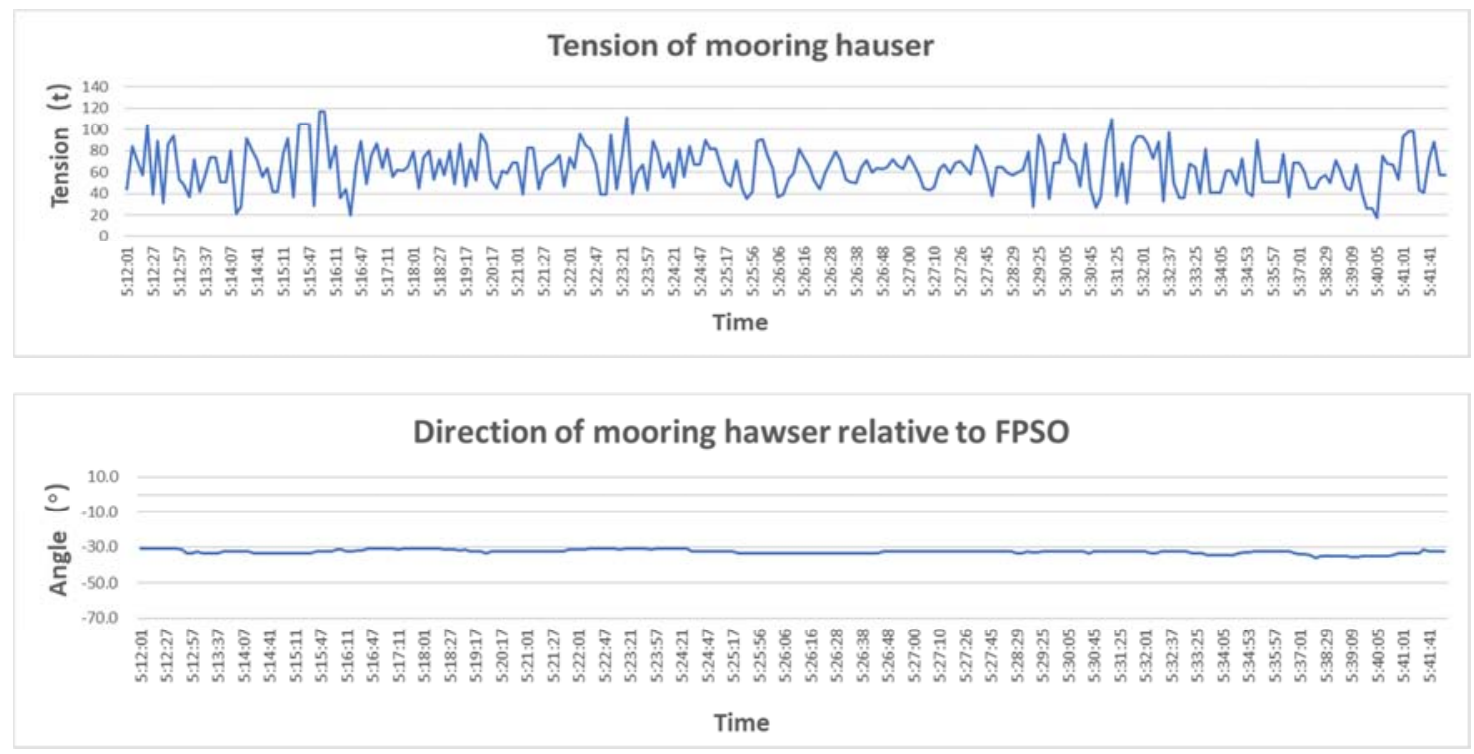

(c) The time history curves of the force exerted by mooring hawser in scenario SA-06.

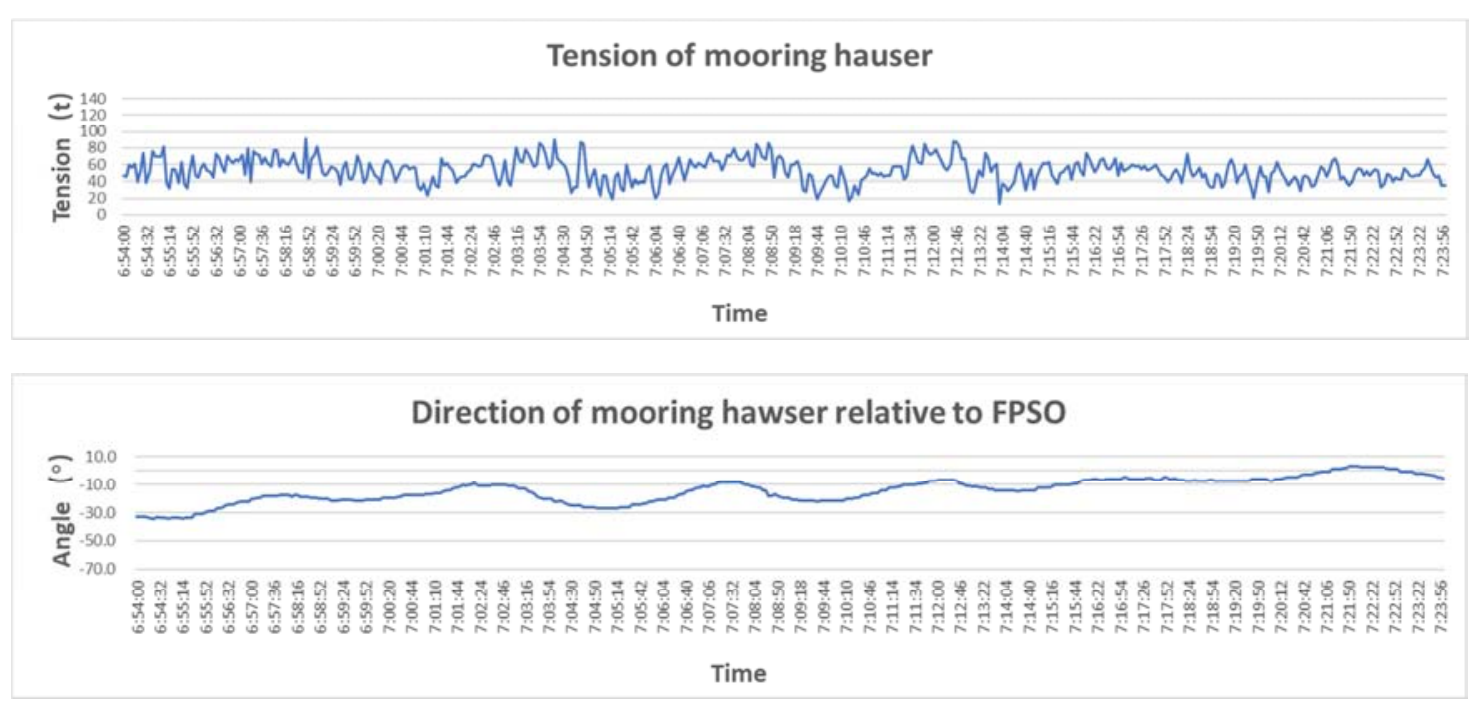

(d) The time history curves of the force exerted by mooring hawser in scenario SA-07.

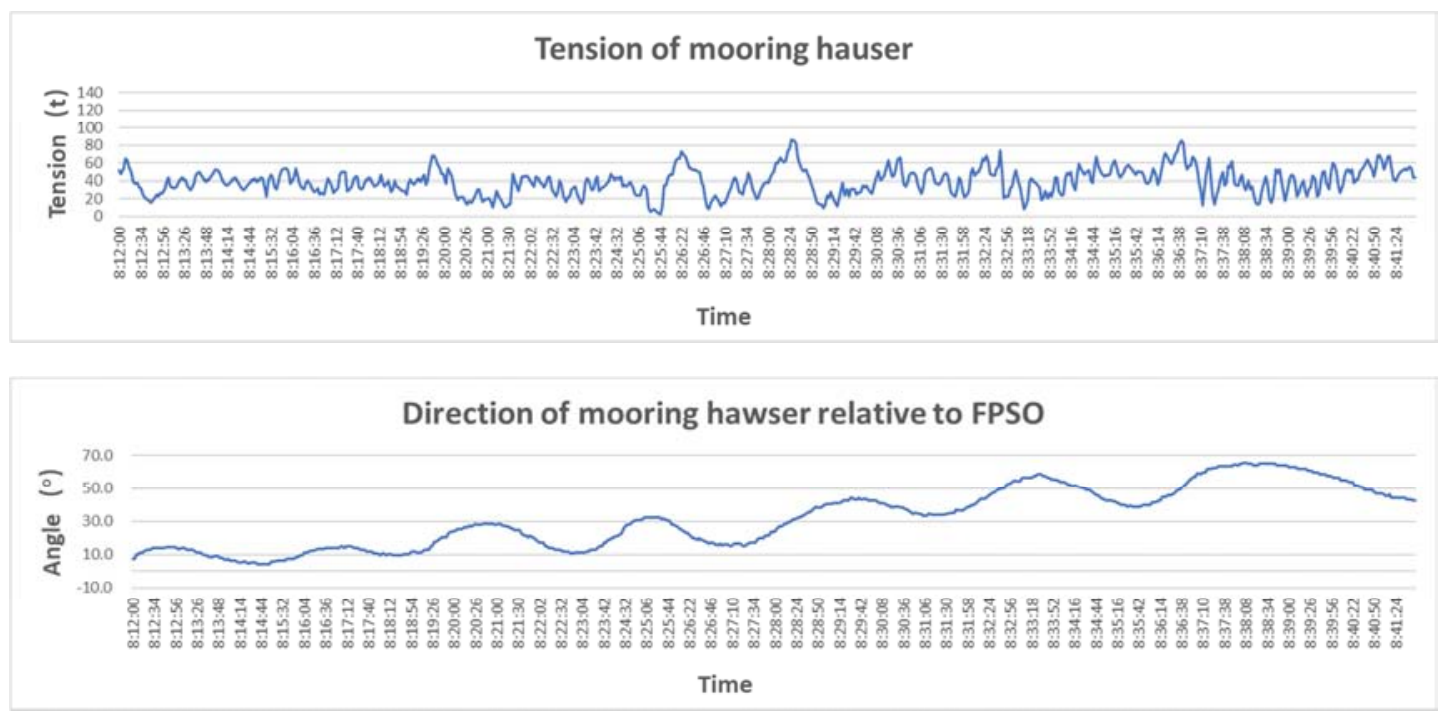

(e) The time history curves of the force exerted by mooring hawser in scenario SA-08.

Figure 7. The time history curves of the force exerted by mooring hawser under different offloading conditions. 
A comparison of the results simulated through scenarios SA-04, SA-05, SA-06, SA-07 and SA-08 shown in the Table 6 and Figure 7 indicates that, with the increase of the relative bearing of wind, the variation of direction of mooring hawser relative to FPSO increases, it becomes more difficult to keep the berthing in stable state. When the relative bearing of wind is greater than $90^{\circ}$, i.e. wind blows from abaft beam of the shuttle tanker, the berthing lies in unstable state. In order to keep the berthing in stability, it needs to frequently adjust the direction and magnitude of the towing force exerted by tugs, the greater the relative bearing of wind, the more frequent the adjustment. The berthing can achieve in the stable status under scenarios SA-04 and SA-05 and all parameters are within the safe permit range, while that under SA-06 is still available, but the tension of the mooring hawser close to the safety margin. If the other parameters remain constant, it needs to frequently adjust the towing force exerted by tug A in order to maintain the stability state under scenario SA-07. Under scenario SA-08, it needs to frequently adjust the towing forces exerted by both tugs to keep the berthing of the shuttle tanker, and the direction of the mooring hawser relative to FPSO is out of the marginal scope. Therefore, the working conditions under scenario SA-04 and SA-05 are better choices, while those under scenario SA-07 and SA-08 are worse ones, they are on an unstable equilibrium.

\subsubsection{Determination of Critical Wind Speed Under the Unfavorable Offloading Condition and Unfavorable Wind Direction}

Due to offloading system being extremely unstable and in dangerous state if the wind blows from abaft beam of the shuttle tanker, which needs to frequently adjust the towing force exerted by tugs to ensure the safety, no attempt will be carried out with the increase of the wind speed. If the wind blows from abaft beam of the shuttle tanker, it is recommended to shift the offloading operation to the opposite side. The simulations are further conducted with the increase of the port beam wind speed to $10 \mathrm{~m} / \mathrm{s}$ (20 kts) and $12 \mathrm{~m} / \mathrm{s}$ (24 kts). The results obtained from the abovementioned experiments will determine if it is necessary to do with the further increase of wind speed to $14 \mathrm{~m} / \mathrm{s}$ (28kts), 16 $\mathrm{m} / \mathrm{s}$ (32 kts). The scenarios designed as shown in Table 7.

Table 7. Designed scheme of simulated scenarios.

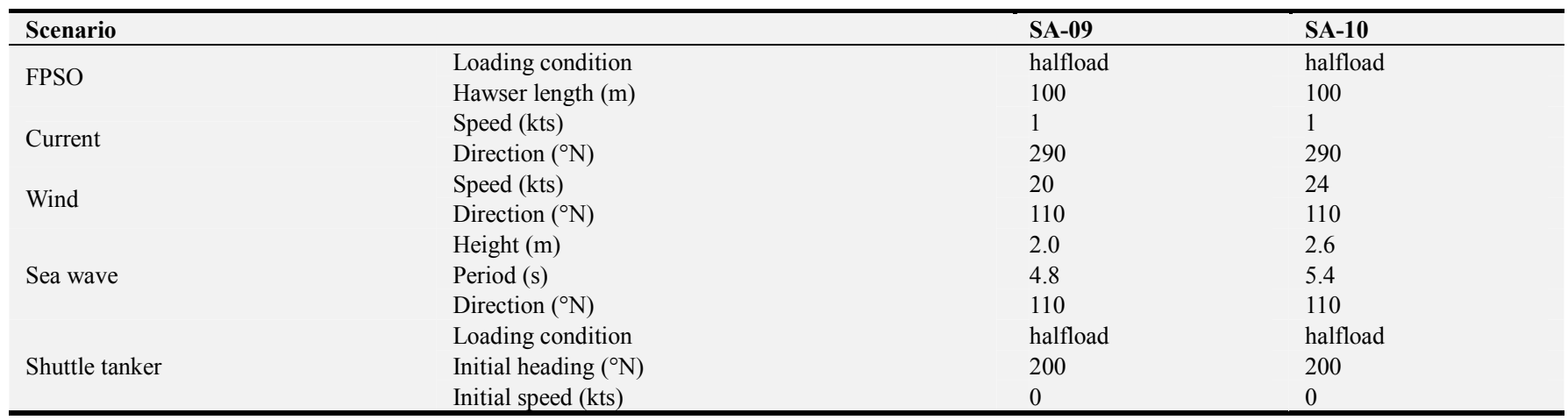

The values of evaluation parameter obtained from simulated scenarios listed in Table 7 are shown in Table 8 , and the time history curves of force exerted by the mooring hawser are shown in Figure 8.

Table 8. Test results with the increase of port beam wind speed under B status.

\begin{tabular}{lll}
\hline Index parameter / Scenario & SA-09 & SA-10 \\
\hline Max tension of mooring hawser $(t)$ & 105 & 117 \\
The frequency of force 100 t or more acting upon the mooring hawser in any half an hour & 3 & 12 \\
Direction of mooring hawser relative to FPSO $\left(^{\circ}\right)$ & $(-20,-10)$ & $(-11,+8)$ \\
Towing force of tug A $(t)$ & 40 & $(25,40)$ frequent adjustment \\
Towing force of tug B $(t)$ & 240 & $(35,40)$ \\
Direction of towing hawser of tug A relative to shuttle tanker $\left(^{\circ}\right)$ & 200 & 240 \\
Direction of towing hawser of tug B relative to shuttle tanker $\left(^{\circ}\right)$ & 40 & $(200,205)$ \\
Angle between both towing hawsers $\left(^{\circ}\right)$ & 30 \\
\hline
\end{tabular}

\section{Tension of mooring hauser}

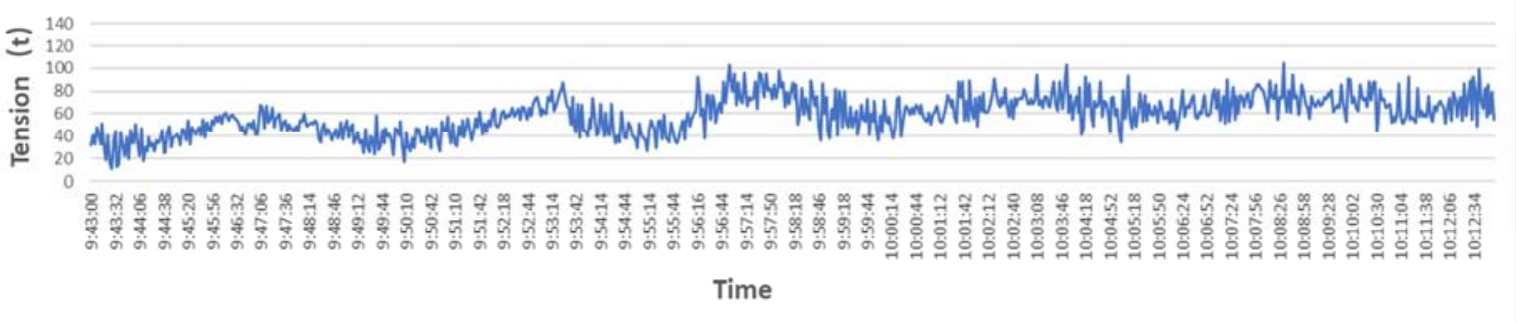




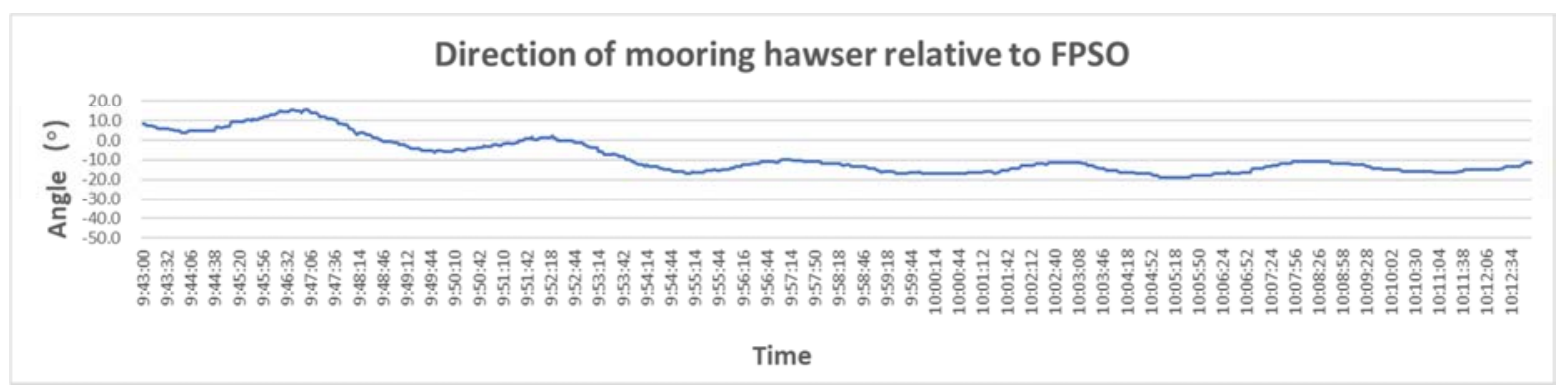

(a) The time history curves of the parameter force exerted by mooring hawser in scenario SA- 09 .
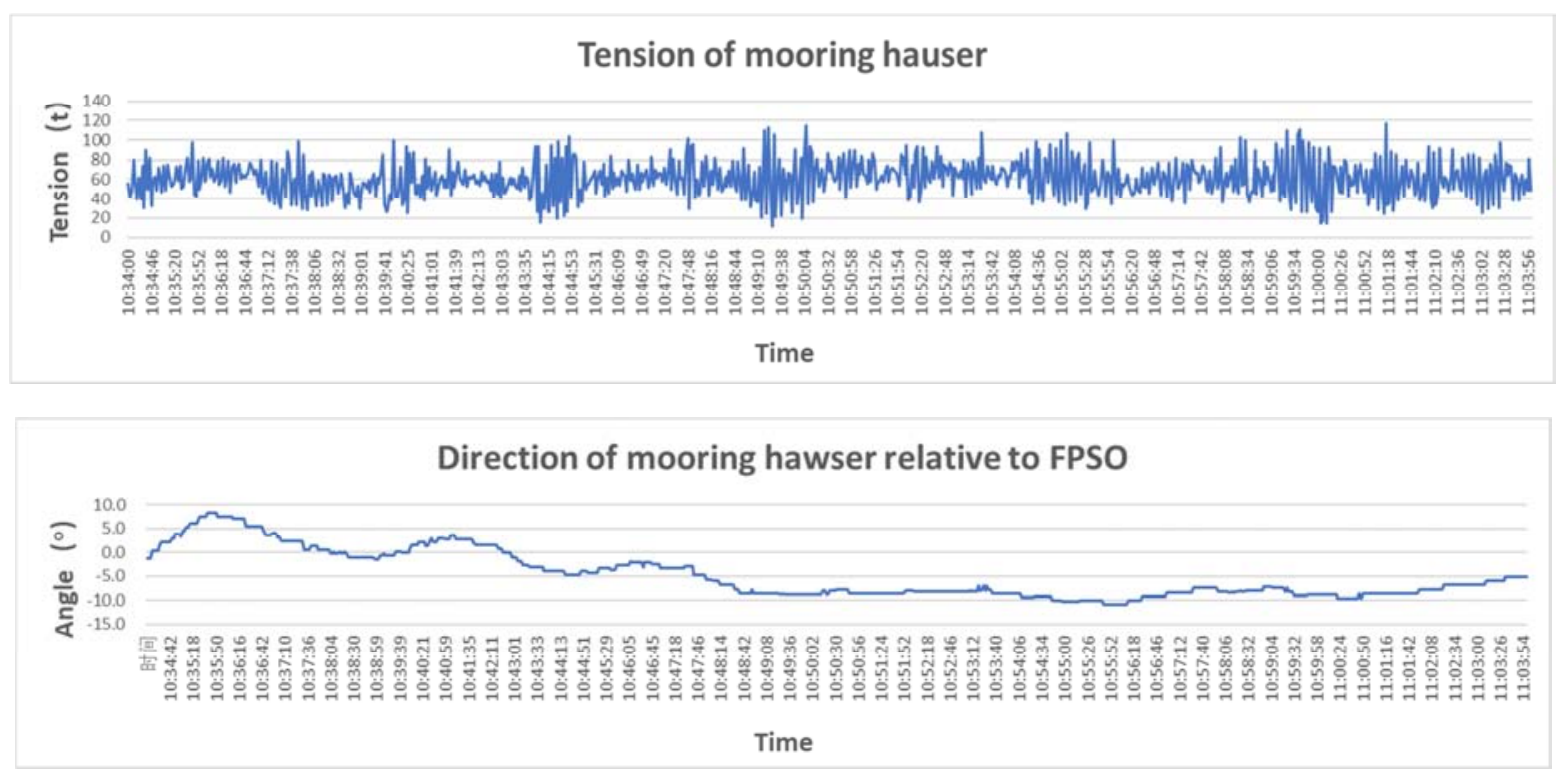

(b) The time history curves of the parameter force exerted by mooring hawser in scenario SA-10.

Figure 8. The time history curves of the force exerted by mooring hawser with the increase of port beam wind speed.

A comparison of the results simulated through scenarios SA-09 and SA-10 shown in the Table 8 and Figure 8 indicates that, when the port beam wind speed increases to 20 $\mathrm{kts}$, the frequency of force $100 \mathrm{t}$ or more acting upon the mooring hawser in any half an hour arrives at 3 , close to critical value; while wind speed to $24 \mathrm{kts}$, the frequency reached as much as 12 , the offloading operation under berthing become unsafe. It can be judged that, under berthing, the maximum speed of the wind abeam is $20 \mathrm{kts}$, thus, no attempt is carried out with greater wind speed.

\section{Conclusion}

This article depicts the simulation experiment of offloading operation between the cylindrical FPSO and shuttle tanker with different loading condition and under the influence of external environment such as winds, waves and currents, etc. Through the calculation of coupled response among the cylindrical FPSO, shuttle tanker and tugs, index parameters required are worked out, such as the magnitude of tension exerted by mooring hawser and its direction relative to the cylindrical FPSO, the magnitude of tension exerted by each towing hawser and its direction relative to the shuttle tanker, etc. Through the analysis of controllability and berth available of offloading operation system with the assistance of both tugs, it works out the most unfavorable loading condition, unfavorable wind direction and the critical wind speed allowing for safe offloading operation. The data obtained from simulation is consistent with the actual situation of cylindrical FPSO offloading operation. In the future, the offloading operation analysis of cylindrical FPSO under sudden severe sea conditions, such as soliton, spuall or strong convection, is worth further study.

\section{References}

[1] Zheng, C. R.; Fan, J.; Miao, G. P.; Zhu, R. C.; Yuan, M. "Coupled dynamic analysis of a deep water FPSO in time domain." in Chinese Journal of Hydrodynamics 2012, 27 (04), pp. 376-382. http://dx.doi.org/10.3969/j.issn10004874.2012.04.002.

[2] Liu, B. "Adaptablity analysis of cylindriacal FWPSO under environmental conditions in the South China Sea." in China Offshore Oil and Gas 2019, 31 (4), pp. 154-158. http://dx.doi.org/10.11935/j.jssn.1673-1506.2019.04.020.

[3] William B. Lamport; Per M. Josefsson. "The next generation of round fit-for-purpose hull form FPSOs offers advantages over traditional ship-shaped hull forms." in DeepGulf Conference 2008, 12. 
[4] Wu, J. M. "Distinguishing Feature and Existing Circumstances of FPSO." in SHIP ENGINEERING 2012, 34 (2), pp. 1-4+102. http://dx.doi.org/10.13788/j.cnki.cbgc.2012.s2.025

[5] C. L. Siow, J. Koto, H. Yasukawa, A. et al. "Wave induce motion of round shaped FPSO." in Journal of Subsea and Offshore 2015, 03 (01), pp. 9-17.

[6] Siow, C.; Koto, Jaswar; Yasukawa, et al. "Mooring Effect on Wave Frequency Response of Round Shape FPSO." In Jurnal Teknologi (Sciences \& Engineering) 2015, 74 (5), pp. 59-68. http://dx.doi.org/10.11113/jt.v74.4642

[7] Marcos Cueva; Fernando Faria.et al. "Model tests and simulations on circular shaped FPSO with drytree solutions."'in SNAME 16th Offshore Symposium. 2010.

[8] Wang F. "Study on key problems of floating manufacture the cylinder deep water offshore oil platform". in Jiangsu University, Zhenjiang, China, 2013.

[9] Tong B.; Ji, X. J.; Wang, H. et al. "Study on damping performances of damping structures of cylindrical FPSO." in The Ocean Engineering 2018, 36 (5), pp. 22-29. http://dx.doi.org/10.16483/j.issn.1005-9865.2018.05.003

[10] Ma, X. Y. "Investigation on the hydrodynamic characteristics of round shaped FPSO induced by freak wave." in Dalian University of Technology, Dalian, China, 2017.
[11] Ji, X. J.; Li, Y.; Tang, Y. G.; Tong, B. "Viscous damping effect and vortex shedding performance of the novel anti-motion structures on a cylindrical FPSO." in Ocean Engineering 2019, $190 \quad$ (C), 106430, ISSN pp.0029-8018. http://dx.doi.org/10.1016/j.oceaneng.2019.106430

[12] Afriana R. "Coupled dynamic analysis of cylindrical FPSO, moorings and riser based on numerical simulation [D]" in University of Stavanger, Norway, 2011.

[13] Jiang M, Li D, Wang Z, et al. "Hydrodynamic Study on the Damping Characteristics of Cylindrical FPSO With the Heave Plate" in ASME 2020 39th International Conference on Ocean, Offshore and Arctic Engineering. American Society of Mechanical Engineers Digital Collection, 2020.

[14] Vidic-Perunovic J, Lee L, Glomnes E B, et al. "Ultradeepwater production system: model test study of cylindrical FPSO in GoM hurricane conditions" in Offshore technology conference. Offshore Technology Conference, 2017.

[15] Han K W, Yusof A F M, Julkipli A M H, et al. "NUMERICAL SIMULATION ON MOTION OF SEVEN CYLINDRICAL FPSO IN DIFFERENT LOADING CONDITIONS". in Journal of Marine Science, Engineering \& Technology. JMSET 2019, Vol 2. Webpage: https://jmset.rina-imarestmjbsc.org

[16] BV. NI 493 Guidance Note "Classification of Mooring Systems for Permanent Offshore Units". 2008. 